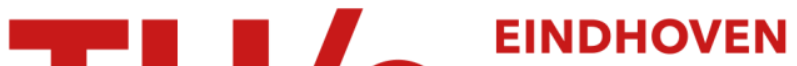 UNIVERSITY OF TECHNOLOGY
}

\section{Non-isothermal kinetics of zeolite water vapor adsorption into a packed bed lab scale thermochemical reactor}

\section{Citation for published version (APA):}

Gaeini, M., Zondag, H. A., \& Rindt, C. C. M. (2014). Non-isothermal kinetics of zeolite water vapor adsorption into a packed bed lab scale thermochemical reactor. In Proceedings of the 15th International Heat Transfer Conference (IHTC-15), August 10-15, 2014, Kyoto, Japan (pp. IHTC15-9169-1/11). Begell House Inc..

Document status and date:

Published: 01/01/2014

\section{Document Version:}

Publisher's PDF, also known as Version of Record (includes final page, issue and volume numbers)

\section{Please check the document version of this publication:}

- A submitted manuscript is the version of the article upon submission and before peer-review. There can be important differences between the submitted version and the official published version of record. People interested in the research are advised to contact the author for the final version of the publication, or visit the $\mathrm{DOI}$ to the publisher's website.

- The final author version and the galley proof are versions of the publication after peer review.

- The final published version features the final layout of the paper including the volume, issue and page numbers.

Link to publication

\section{General rights}

Copyright and moral rights for the publications made accessible in the public portal are retained by the authors and/or other copyright owners and it is a condition of accessing publications that users recognise and abide by the legal requirements associated with these rights.

- Users may download and print one copy of any publication from the public portal for the purpose of private study or research.

- You may not further distribute the material or use it for any profit-making activity or commercial gain

- You may freely distribute the URL identifying the publication in the public portal.

If the publication is distributed under the terms of Article 25fa of the Dutch Copyright Act, indicated by the "Taverne" license above, please follow below link for the End User Agreement:

www.tue.nl/taverne

Take down policy

If you believe that this document breaches copyright please contact us at:

openaccess@tue.nl

providing details and we will investigate your claim. 


\title{
NON-ISOTHERMAL KINETICS OF ZEOLITE WATER VAPOR ADSORPTION INTO A PACKED BED LAB SCALE THERMOCHEMICAL REACTOR
}

\author{
M. Gaeini, ${ }^{1}$ H.A. Zondag, ${ }^{1,2}$ C.C.M.Rindt ${ }^{1, *}$ \\ ${ }^{1}$ Eindhoven University of Technology, Department of Mechanical Engineering, P.O.Box 513, 5600MB \\ Eindhoven, The Netherlands. \\ ${ }^{2}$ ECN, Energy Research Centre of the Netherlands, P.O. Box 1, 1755 ZG Petten, The Netherlands.
}

\begin{abstract}
Replacing fossil fuels by solar energy is of high interest to reduce climate change and depletion of fossil fuel resources. However, to reach high solar fractions, storage of solar energy is necessary. A reliable method for long term solar heat storage is to use thermochemical materials, TCMs. The process is based on a reversible adsorption-desorption reaction, which is exothermic in one direction (hydration) and endothermic in the reverse direction (dehydration). In this research, a lab-scale prototype thermochemical heat storage system was tested. In the experimental setup, moist air enters a reactor vessel filled with dehydrated zeolite $13 \mathrm{X}$. The temperature profile is measured as a function of time both along the flow direction and perpendicular to the flow. Input and output temperatures, pressures and humidity are measured. In addition, a thermal model is developed for the packed bed during the hydration of the zeolite. The model includes mass and heat transfer in the gas, the packed bed and the reactor wall, as well as the adsorption reaction of water vapor on the zeolite which is described by a Linear Driving Force model. Equilibrium constants are modeled as a function of temperature. By comparing the temperatures of the experimental investigation with the results of the numerical simulation model, the kinetic parameters for the adsorption in non-isothermal and non-adiabatic conditions are found. In the near future, the developed numerical model will be used to simulate the heat and vapor transport processes in a large-scale reactor system.
\end{abstract}

KEY WORDS: Thermal storage, Adsorption and desorption, Heat and mass transfer, Fixed bed reactor, Kinetics and equilibrium, Thermochemical material

\section{INTRODUCTION}

According to the International Energy Agency (IEA), the building sector is the largest consumer of energy and accounts for approximately $40 \%$ of the world's total primary energy consumption, which is equal to 2794 million tons of oil equivalent (Mtoe), and $24 \%$ of the world's total $\mathrm{CO}_{2}$ emission [13]. Therefore, significant reductions in fossil fuel consumption are possible by using renewable energy sources in this sector.

In recent years, studies have been done to reach a low-energy building concept. The passive house concept, which was developed first in Germany [16], is one of the leading concepts. Some other low-energy demonstration projects are described in [10] and [15]. Net zero energy building projects demonstrate that reducing total energy consumption of a house is possible using new innovative solar energy technologies, which in the case of increase in price of energy would be profitable compared to conventional energy-saving technologies

*Corresponding C.C.M.Rindt: C.C.M.Rindt@tue.nl 
[14]. Solar energy is one of the most promising sustainable energy sources for replacing fossil fuels. It can be used in residential buildings by means of different methods, such as solar collectors, PV panels and passive design. Since both the solar irradiation and the energy demand show large variations during a year that are asynchronous, energy storage is necessary to make effective use of the available solar energy [6].

In the case of using solar energy in the built environment, long-term heat storage is needed to overcome the seasonal mismatch between heating demand and solar energy supply. Conventional heat storage methods have considerable heat losses and relatively low energy storage density. Heat storage by means of a reversible reaction $(A+B \leftrightarrow A B+$ heat $)$ has comparatively higher energy storage density and almost no heat loss. Heat generated by a solar collector during summer can be stored in an endothermal dissociation reaction of a thermochemical materials into two components (charging), and the energy stored in this way can be released during winter by the reverse exothermal reaction between the components (discharging). An interesting reactant should be low cost, non-toxic, non-corrosive and stable with high energy storage density [20]. A candidate fulfilling these requirements is zeolite which can adsorb and desorb water vapor in an efficient and reversible way. However, zeolite is relatively expensive compare to other materials, but it is a good candidate to be used in scientific studies because of its stability.

The most important part of the system which can provide such long-term heat storage for a residential building is the reactor. The advantage of using a fixed-bed reactor is the low need of auxiliary energy in comparison with other types of reactors such as fluidized bed or screw reactors. Here, an open atmospheric packed bed reactor on lab-scale is chosen for the experiments because of its simplicity and low costs compared to other types of systems [21]. Some disadvantages of using a packed bed reactor are limited mass and heat transfer inside the bed which needs to be considered in the design of the reactor for large scale systems. In order to study the applicability of thermochemical heat storage, several experiments are done in the lab-scale reactor. Humid air flows through the reactor and depending on the air temperature and humidity adsorption takes place leading to the release of the stored energy. In a practical real system with application in the built environment, a borehole system can be employed as the humidifier, but in this study a lab-scale controlled mixer is used to provide humid air.

A lab-scale reactor was built and tested.However, for further optimization and upscaling the lab-scale reactor, a model is needed to predict the performance of the reactor. In literature, several models are developed for the water vapor adsorption into zeolite. Ahn and Lee [1] studied the effect of capillary condensation on adsorption and thermal desorption of water in zeolite, by considering an elaborate model for the equilibrium amount of adsorbed water. Dawoud et al. [5] developed a non-isothermal model for adsorption of water vapor into a consolidated zeolite layer and studied the micro-pore diffusion. The applicability of the adsorption-desorption loops of the water-zeolite system is studied by developing models in [7] and [19].

The purpose of this study is to understand the effects of the kinetic parameters for the adsorption of water on Zeolite $13 \mathrm{X}$ on the performance of the packed bed reactor. The equilibrium amount of adsorbed water in a zeolite $13 \mathrm{X}$ bed at various partial pressures of water vapor is modeled based on experimental data provided by the manufacturer. The performance of the bed is studied experimentally and then compared with the mathematical model incorporating the kinetic model and isotherm curves and including the heat losses from the side wall of the reactor. From this work, predictions of the thermal dynamics of an adsorption bed on reactor scale can be achieved, which can be used for further studies on the design and optimization of a thermochemical heat storage system.

\section{MATHEMATICAL MODEL}

In this paper, the focus is on hydration of zeolite. The system studied is a fixed packed bed reactor filled with spherical zeolite $13 \mathrm{X}$ beads, in which the adsorption of water takes place. The feed gas is humid air with a temperature of $14^{\circ} \mathrm{C}$ which is supplied to the bed with initial temperature of $21^{\circ} \mathrm{C}$ (ambient temperature). A 
non-isothermal and non-adiabatic model including mass and energy transfer equations are developed to study the thermal dynamics of the system.

\subsection{Mass and Heat Balances}

The equations which describe the dynamics of the system are under some applied assumptions in the model: (a) the flow in the reactor can be described by an axially dispersed plug flow model; (b) radial gradients in the bed are negligible, therefor heat and mass transfer balances are considered as one-dimensional problems; (c) the gas phase behaves as an ideal gas and is in thermal equilibrium with solid phase; (d) the adsorbent beads have identical characterizations and the bed properties are uniform.

By considering these assumptions, the governing heat and mass balances can be written by a set of PDEs along the vertical coordinate $(z)$ and the time $(t)$, as follow:

The overall mass balance is expressed based on the air density, $\rho_{\text {air }}$ :

$$
\frac{\partial \rho_{a i r}}{\partial t}+u \frac{\partial \rho_{a i r}}{\partial z}=0
$$

where $u$ is the velocity.

The water mass balance is expressed based on the water vapor concentration, $c$ :

$$
\frac{\partial c}{\partial t}+u \frac{\partial c}{\partial z}-D_{z} \frac{\partial^{2} c}{\partial z^{2}}+\frac{\left(1-\epsilon_{b}\right)}{\epsilon_{b}} \rho_{p} \frac{d \bar{q}}{d t}=0
$$

where $\epsilon_{b}$ is the bed porosity, $\rho_{P}$ is the particle density, $\bar{q}$ is the averaged amount of adsorbed water per $\mathrm{kg}$ of zeolite and $D_{z}$ the axial dispersion coefficient. This coefficient is derived from Wakao's correlation [18] for fast reactions in which mass transfer between the particle and the fluid surrounding the particle is the rate controlling step:

$$
\frac{\epsilon_{b} D_{z}}{D_{M}}=20+0.5 R e S c
$$

where $D_{M}$ is the molecular diffusivity, $\operatorname{Re}\left(\rho_{g} \epsilon_{b} u d_{p} / \mu_{g}\right)$ and $S c\left(\mu_{g} / \rho_{g} D_{M}\right)$ are Reynolds and Schmidt dimensionless numbers, respectively.

The energy balance in the bed is given by:

$$
\overline{\rho C_{P}} \frac{\partial T}{\partial t}+\epsilon_{b} \rho_{g} C_{P, g} u \frac{\partial T}{\partial z}-k_{e f f} \frac{\partial^{2} T}{\partial z^{2}}-\left(1-\epsilon_{b}\right) \rho_{p} \frac{d \bar{q}}{d t} \Delta H+\frac{4 h_{i}}{d_{i}}\left(T-T_{w}\right)=0
$$

Here, $\overline{\rho C_{P}}$ is the overall volumetric heat capacity of the bed. which is given by:

$$
\overline{\rho C_{P}}=\epsilon_{b} \rho_{g} C_{P, g}+\left(1-\epsilon_{b}\right) \epsilon_{p} \rho_{g} C_{P, g}+\left(1-\epsilon_{b}\right) \rho_{p} C_{P, s}+\left(1-\epsilon_{b}\right) \rho_{p} \bar{q} C_{P, \text { water }} M_{\text {water }}
$$

The overall volumetric heat capacity consists of the heat capacity of the air in bed voids (first term), the heat capacity of the air in beads pores (second term), the heat capacity of the solid (third term) and the heat capacity of the adsorbed water (fourth term). 
The effective thermal conductivity, $k_{e f f}$, can be estimated by the model of Zehner and Schlünder [8]. The model is satisfactory over a broad range of solid-to-fluid thermal conductivities and solid fractions. In the model, the effective thermal conductivity is expressed as:

$$
\frac{k_{e f f}}{k_{g}}=1-\sqrt{1-\epsilon_{b}}+\frac{2 \sqrt{1-\epsilon_{b}}}{1-\lambda B}\left(\frac{(1-\lambda) B}{(1-\lambda B)^{2}} \ln \left(\frac{1}{\lambda B}\right)-\frac{B+1}{2}-\frac{B-1}{1-\lambda B}\right) ; B=1.25\left(\frac{1-\epsilon_{b}}{\epsilon_{b}}\right)^{10 / 9}
$$

with $\lambda=k_{g} / k_{p}$ the gas to particle conductivity ratio, and $B$ the shape factor which can be approximated for spherical particles as above.

In equation 4, the last term represents heat loss power from the reactor wall per unit of the reactor volume. The heat loss through the reactor is modeled by considering the wall temperature and the thermal mass of the reactor wall in another energy balance for the reactor wall:

$$
A_{w} \rho_{w} C_{P, w} \frac{\partial T_{w}}{\partial t}=\pi d_{i} h_{i}\left(T-T_{w}\right)-\pi d_{o} h_{o}\left(T_{w}-T_{a m b}\right)
$$

in which $d_{i}$ and $d_{o}$ refer to the inner and outer diameters of the reactor, $h_{i}$ and $h_{o}$ represent the heat transfer coefficients at the inner and outer side of the wall, and $A_{w}$ is the cross sectional area of the body of the reactor wall.

Cooling at the external surface is normally by natural convection and the value of the external heat transfer coefficient, $h_{o}$, can be calculated from the Nusselt number at outside wall of the reactor, $N u_{o}$, which is given approximately by [2]:

$$
N u_{o}=\left(2+\frac{0.387 R a^{1 / 6}}{\left(1+(0.492 / P r)^{9 / 16}\right)^{8 / 27}}\right)^{2}
$$

where $R a$ and $P r$ are Rayleigh and Prandtl numbers, evaluated at the average temperature between ambient temperature and surface temperature $\left(T_{a i r}=\left(T_{w}+T_{a m b}\right) / 2\right)$.

The heat transfer coefficient at the internal surface of a porous bed can be estimated from Leva's correlation [9]:

$$
N u_{i}=0.813 R e^{0.19} e^{-6 d_{p} / d_{i}}
$$

For metal-walled reactors without insulation, the heat transfer resistance of the wall can generally be neglected.

\subsection{Kinetics Models}

For many adsorption systems, the diffusion-controlled kinetics may be satisfactory represented by the Linear Driving Force (LDF) approximation [11]:

$$
\frac{d \bar{q}}{d t}=k_{m}\left(q_{e q}-\bar{q}\right)
$$

where $\bar{q}$ and $q_{e q}$ are the adsorbed and equilibrium mol of water in solid phase per kilograms of dry zeolite, and 
$k_{m}$ is the mass transfer coefficient. The effect of LDF approximation is compared with another approximation presented by Vermeulen [17]:

$$
\frac{d \bar{q}}{d t}=k_{m} \frac{\left(q_{e q}^{2}-\bar{q}^{2}\right)}{2 \bar{q}}
$$

In real adsorption systems, several mass transfer resistances contribute to the overall kinetics. The mass transfer coefficient, $k_{m}[1 / s]$, is a lumped parameter that considers the external film resistance, the macropore resistance and the micropore resistance [11]:

$$
k_{m}=\left(\frac{d_{p}}{6 k_{f}}+\frac{d_{p}^{2}}{60 \epsilon_{b} D_{P}}\right)^{-1}
$$

The mass transfer coefficient for the external film of fluid around the particle, $k_{f}$, can be obtained from the Sherwood number. A correlation for the Sherwood number is expressed by Wakao and Funazkri in the range of Reynolds numbers from about 3 to 10000 [18]:

$$
S h=2+1.1 S c^{1 / 3} R e^{0.6}
$$

The macropore diffusivity, $D_{P}$, is given by [4]:

$$
D_{p}=\frac{1}{\tau}\left(\frac{1}{D_{M}}+\frac{1}{D_{K}}\right)^{-1}
$$

where $\tau$ is the tortuosity factor and $D_{M}$ and $D_{K}$ are the molecular and Knudsen diffusivity, respectively. The molecular diffusivity for the binary gas mixture of air and water is evaluated from the Chapman-Enskog theory equation [3] and the Knudsen diffusion is calculated from the kinetic theory formula [4].

\subsection{Equilibrium Models}

The adsorption of water vapor on zeolite $13 \mathrm{X}$ is reported to be type 2 isotherm of Brunauers classification, however at lower pressures it behaves as type 1 [12]. Here, the water uptake on zeolite 13XBFK (from CWK Chemiewerk Bad Kstritz $\mathrm{GmbH}$ ) is studied and the equilibrium loading of water in the adsorbed phase, $q_{e q}$, on zeolite is estimated by the Langmuir and the Langmuir-Freundlich isotherms:

$$
q_{e q}=\frac{q_{\max } b P^{n}}{1+b P^{n}} ; b=b_{0} \exp (\Delta E / R T)
$$

where $q_{\max }$ is the maximum amount of adsorbed water, and $b$ and $n$ are temperature-dependent parameters. For the Langmuir model $n=1$. For the Langmuir-Freundlich model $n$ is given by:

$$
n=n_{1}+\frac{n_{2}}{T}
$$

Limited information about the water uptake on zeolite 13XBFK is provided by the manufacturer which means more investigation on the material side is needed. Figure 1 presents the isotherms at temperatures of 25, 80 and $95{ }^{\circ} \mathrm{C}$, provided by the manufacturer. The Langmuir-Freundlich isotherm model is fitted through these 


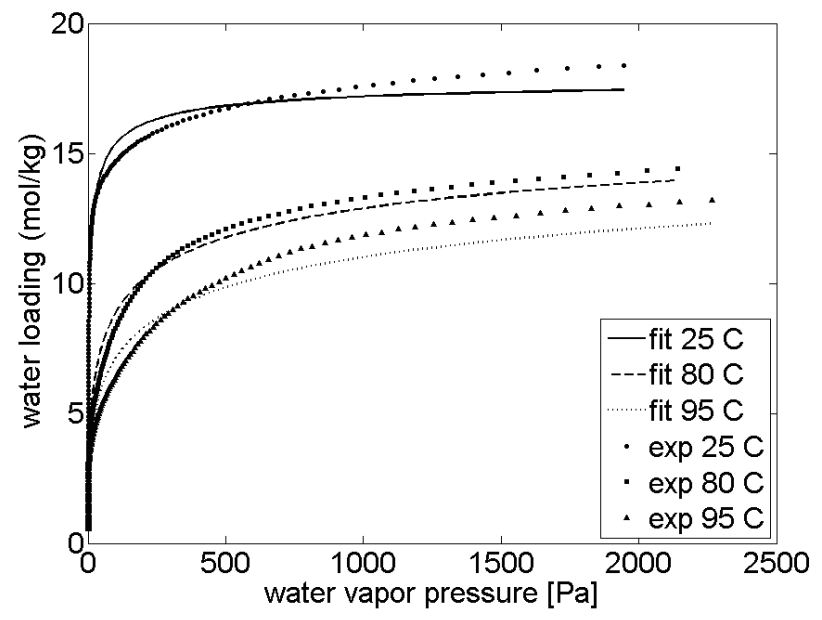

Fig. 1 Langmuir-Freundlich fitted curves on Zeolite 13X water uptake experimental data.

Table 1 obtained fitting parameters for the Langmuir-Freundlich and the Langmuir isotherm models

\begin{tabular}{cccccc} 
& $q_{\max }$ & $b_{0}$ & $\Delta E$ & $n_{1}$ & $n_{2}$ \\
& {$[\mathrm{~mol} / \mathrm{kg}]$} & {$\left[1 / \mathrm{Pa}^{n}\right]$} & $\mathrm{J} / \mathrm{mol}$ & {$[-]$} & {$[\mathrm{K}]$} \\
\hline Langmuir & 18 & 0.0002 & 10000 & 1 & 0 \\
Langmuir-Freundlich & 18 & 0.000308 & 18016 & -0.3615 & 274.23
\end{tabular}

experimental data, and fitting parameters are extracted and presented in Table 1 . The isotherm model with the obtained fitting parameters is generalized for all the temperatures and is implemented in the reactor model.

The parameters which are used in the model, i.e. properties of the adsorbent Zeolite 13X and characteristics of the bed are presented in Table 2 .

Table 2 Properties of the adsorbent Zeolite $13 \mathrm{X}$ and Characteristics of the bed

\begin{tabular}{cc|cc}
\hline Bed porosity $\left(\epsilon_{b}\right)$ & 0.4 & Bed height $(H)$ & $0.1 \mathrm{~m}$ \\
Particle density $\left(\rho_{p}\right)$ & $1040 \mathrm{~kg} / \mathrm{m}^{3}$ & Bed inner diameter $\left(d_{i}\right)$ & $0.07 \mathrm{~m}$ \\
Heat capacity $\left(C_{P, s}\right)$ & $1350 \mathrm{~J} / \mathrm{Kg} \cdot \mathrm{K}$ & Bed outer diameter $\left(d_{o}\right)$ & $0.08 \mathrm{~m}$ \\
Heat of adsorption $(\Delta H)$ & $63 \mathrm{~kJ} / \mathrm{mol}$ & Wall heat capacity $\left(\rho_{w} C_{P, w}\right)$ & $3046400 \mathrm{~J} / \mathrm{m}^{3} . K$
\end{tabular}

\section{EXPERIMENTAL SETUP}

The setup can be divided into three main sections as shown in Figure 2(a). The first section is where the humidity and flow rate of the airflow into the reactor is prepared in a controlled way by means of the GFC (Gas Flow Controller) and CEM (Controlled Evaporator Mixer). For hydration, air flow passes through the CEM where the air is mixed with the water flow coming from the water vessel regulated by a LFC (Liquid Flow Controller). For dehydration, almost dry air flow passes through a heater and the heated air goes to the reactor. At the beginning of the experiment, some time is needed for the system to be stabilized. During the stabilization time, the flow is drained to the ambient through a blow-off pipe.

The second section, the reactor, is the main part of the setup and most of the measurements are done in this part. The outer sell of the reactor body is made of stainless steel. The inner shell of the reactor body is made of Teflon, because of its low thermal conductivity. The air enters the reactor from the top side and leaves the reactor at the bottom. The zeolite is placed on top of a filter at the bottom of the reactor. The positions of the 
17 thermocouples attached to the reactor are shown in Figure 2(b). T1 and T2 measure the inlet and outlet temperature, respectively, and M1 till M5 measure the temperature in the bed. B1 till B5 are attached at the inner side of the Teflon wall. W1 till W5 are used to measure the outer wall temperatures.

In the third section, the temperature and humidity of the outflow are measured. The water content in the outflow of the reactor is monitored by a humidity/temperature sensor which consists of two sensors, one for measuring the temperature and one for measuring the relative humidity. Based on the measured temperature and relative humidity, the water content in the outflow can be calculated. Since large errors in the absolute humidity can occur on measurement of humidity at high temperatures (because a high temperature leads to a low relative humidity and therefore a large relative error in the relative humidity), the sensors are positioned after a chiller. This chiller cools down the outflow by which the relative humidity rises and therefore the absolute humidity can be determined more accurately.

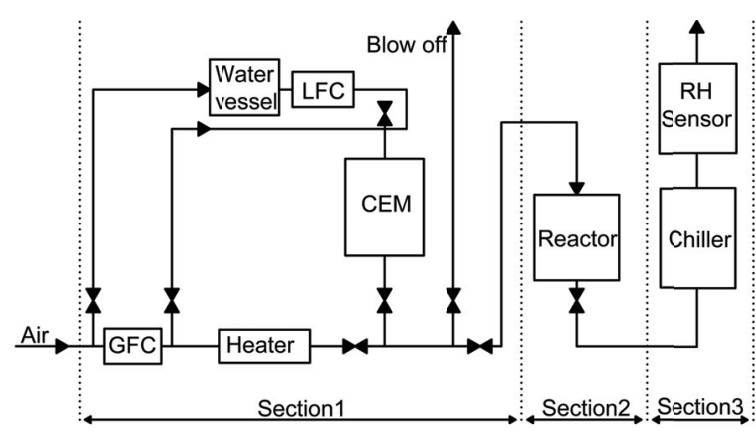

(a) parts of the system

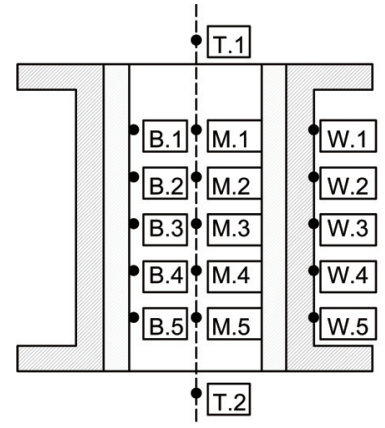

(b) reactor and position of the thermocouples

Fig. 2 Schematic view of the system and the reactor

\section{RESULTS AND DISCUSSION}

Hydration of zeolite is studied numerically and experimentally, and the numerical and experimental results are compared. The adsorption experiments are performed in a wide range of humidity and flow rates, but here, only one of the experiments is presented and compared with the numerical results to validate the model. The operational conditions of the presented adsorption experiment are listed in Table 3. The presented results of this experiment in Figure 3, shows the inlet and outlet temperatures (T1 and T2), and the temperatures at five different heights of the bed (M1, M2, M3, M4 and M5).

The temperature of the bed increases immediately after the start of the experiment because of the reaction in the inlet section of the bed, and the heat is transferred to the downstream sections by means of the flow through the bed. After the reaction is finished in each point, heat generation is stopped and the temperature drops because of the cold air inflow. The temperature at the outlet of the reactor, T2, is equal to the other temperatures until almost $15000 \mathrm{~s}$, when the reaction is finished. After the reaction is finished, the temperature at the corresponding location in the reactor drops to the inlet temperature. The reactor outlet temperature remains high until the last layers of the bed release the sensible heat of the material to the flow. The temperature $\mathrm{T} 1$ is the inlet temperature of the reactor which has a drop at the beginning of the experiment from the ambient temperature $\left(21^{\circ} \mathrm{C}\right)$ to the temperature of evaporation equilibrium between the specific water and air flow rates $\left(14^{\circ} \mathrm{C}\right)$. This slightly higher temperature of the inlet at the beginning of the experiment is possibly the reason for the peaks in all the other temperatures (bed and outlet temperatures).

Several simulations are run with different kinetics, equilibrium fits and mass transfer coefficients in order to investigate the kinetic models and parameters. The simulations are categorized in Table 4 . The first three runs (LDF-LF-1,2 and 3) are compared to investigate the effect of the mass transfer coefficient on the temperature 
Table 3 operational conditions

\begin{tabular}{cc}
\hline Air flow rate & $1 \mathrm{l} / \mathrm{s}$ \\
inlet relative humidity & $25 \%$ \\
Inlet temperature & $14{ }^{\circ} \mathrm{C}$ \\
Ambient temperature & $21^{\circ} \mathrm{C}$
\end{tabular}

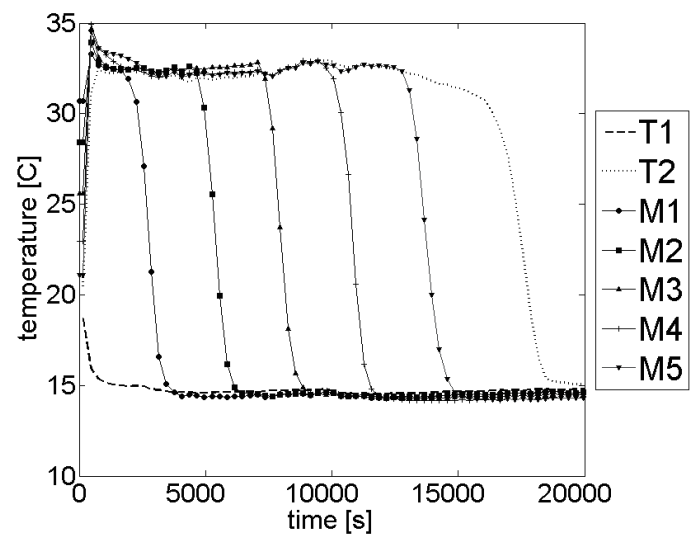

Fig. 3 Experimental data; thermocouples T and M.

profile in the bed, while the LDF-L-1 and VER-LF-1 runs are compared with the LDF-LF-1 run to investigate the effect of equilibrium and kinetics models, respectively. In the model, the temperatures during the process time are calculated for different heights of the bed, corresponding to the locations of the thermocouples in the experimental setup. The result from the LDF-LF-1 run is compared with experimental results in Figure 4(a), which shows the temperatures at five different heights of the reactor (M1, M2, M3, M4 and M5). At the beginning, the numerical results show a large overshoot compared to the experimental results. That is because the equilibrium water loading changes rapidly at low pressures (Figure 1), which results in a large driving force for the reaction to happen. The calculated wall temperature in the model is compared with experimental results in Figure 4(b). The experimental temperatures are higher than the calculated ones, especially when the wall starts to cool down and the temperatures drop. As can be seen, after the peak in temperature the experimental temperatures are closer to each other. This is probably because of the heat conduction in the height direction in the body of the reactor which is neglected in the model. The heat transfer coefficients at the wall need to be investigated more elaborately. The calculated water vapor concentration at the outlet during the hydration experiment is compared with the numerical results in Figure 5.

Table 4 categorized simulations based on kinetics and equilibrium models and mass transfer coefficients

\begin{tabular}{cccc} 
run code & kinetics model & equilibrium fit & mass transfer coefficient $\left[\mathrm{s}^{-1}\right]$ \\
\hline LDF-LF-1 & LDF & Langmuir-Freundlich & $1.5 \times 10^{-3}$ \\
LDF-LF-2 & LDF & Langmuir-Freundlich & $4.0 \times 10^{-3}$ \\
LDF-LF-3 & LDF & Langmuir-Freundlich & $15.0 \times 10^{-3}$ \\
LDF-L-1 & LDF & Langmuir & $1.5 \times 10^{-3}$ \\
VER-LF-1 & Vermeulen & Langmuir-Freundlich & $1.5 \times 10^{-3}$
\end{tabular}

In Figure 6(a),the results from the LDF-LF-1 and VER-LF-1 runs are compared with the experimental results at the third thermocouple in the bed (M3). The comparison shows that the Vermeulen's mass transfer model has a slightly better prediction of the temperature than the LDF model. However the difference is not significant, and by considering the simplicity of the LDF model, it is possibly a reasonable approximation for large systems. 


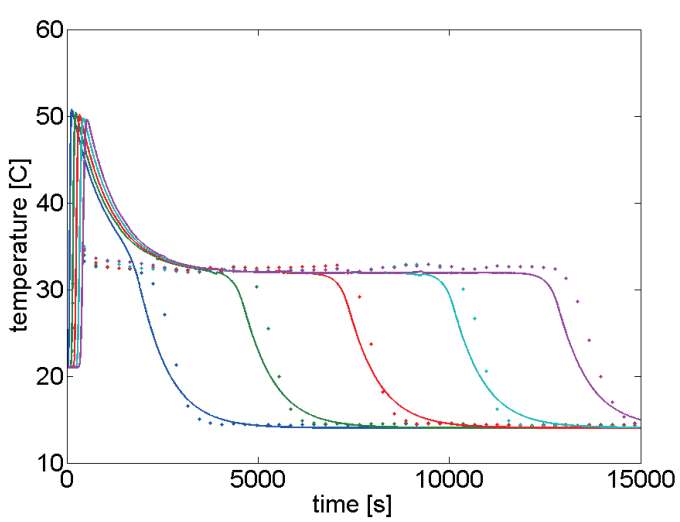

(a) Bed temperatures



(b) Wall temperatures

\begin{tabular}{|c|c|c|c|c|}
\hline $\begin{array}{l}\cdot \operatorname{exp.1} \\
- \text { num.1 }\end{array}$ & $\begin{aligned} & \exp .2 \\
- & \text { num. } 2\end{aligned}$ & $\begin{aligned} & \exp .3 \\
- & \text { num. } 3\end{aligned}$ & $\begin{aligned} & \exp .4 \\
- & \text { num. } 4\end{aligned}$ & 5 \\
\hline
\end{tabular}

Fig. 4 The numerical wall temperature in comparison with experimental results.

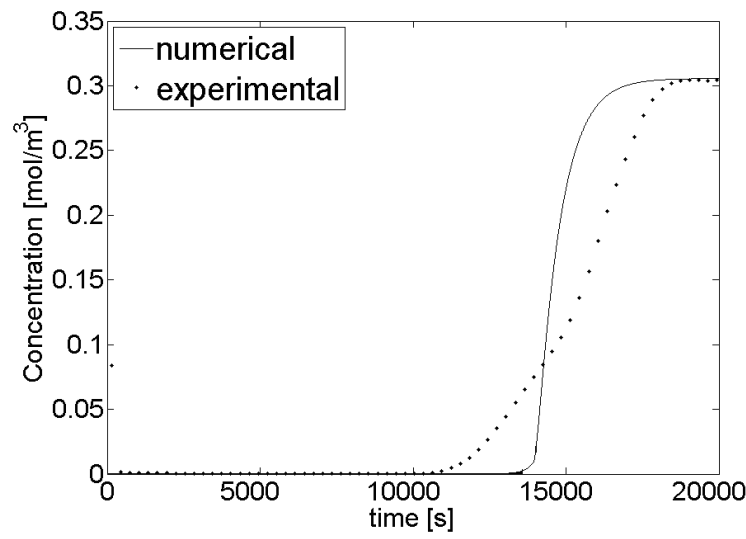

Fig. 5 The numerical concentration at the outlet of the reactor in comparison with experimental results.

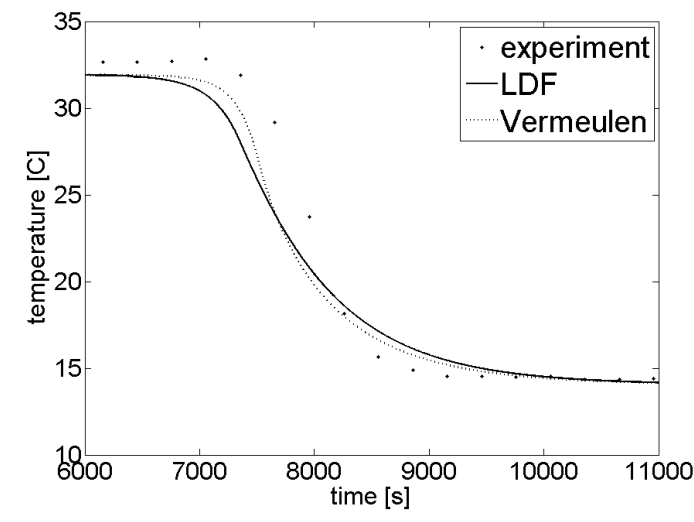

(a) Comparison between LDF and Vermeulen's kinetics model.

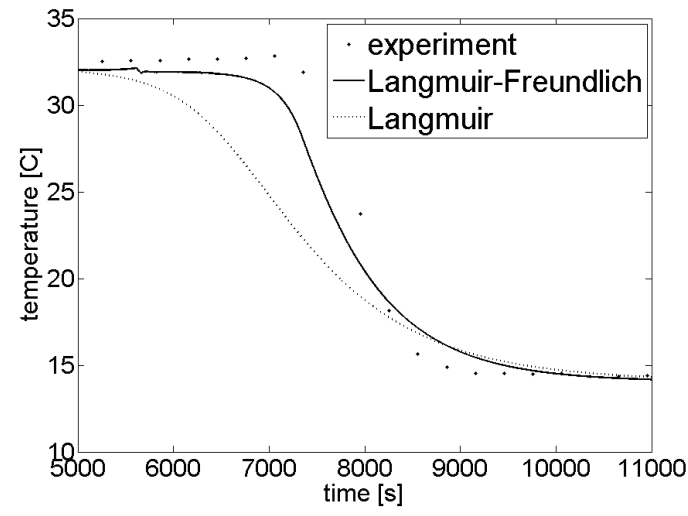

(b) Comparison between Langmuir-Freundlich and Langmuir fit

Fig. 6 Effect of kinetics model and equilibrium fit 


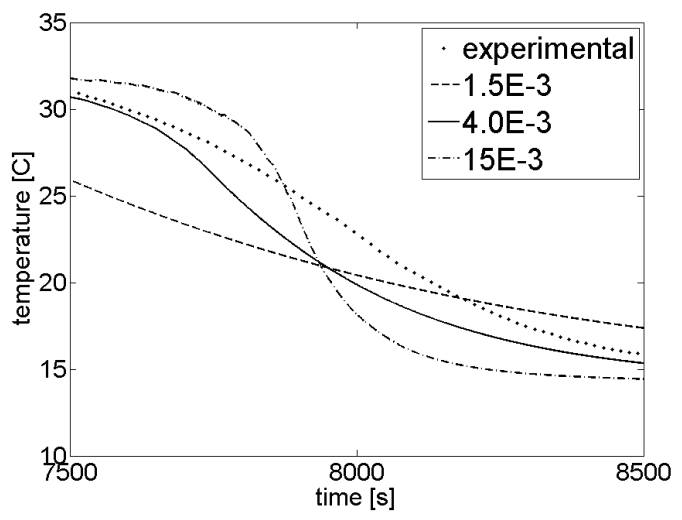

Fig. 7 Comparison between different values of the mass transfer coefficient.

In Figure 6(b), the results from the LDF-LF-1 and LDF-L-1 runs are compared with the experimental results at the third thermocouple in the bed (M3). The Langmuir-Freundlich fit shows a better prediction of the system thermal performance than the Langmuir fit, which is expected according to the higher accuracy of the Langmuir-Freundlich fit. However due to the complexity of the Langmuir-Freundlich equilibrium correlation, the simulation is more time consuming.

The effect of the mass transfer coefficient, $k_{m}$, is investigated in the Figure 7. By increasing the mass transfer coefficient, the temperature drop becomes steeper. The best value for the mass transfer coefficient is estimated to be around $4.0 \times 10^{-3} \mathrm{~s}^{-1}$.

\section{CONCLUSIONS}

A non-isothermal and non-adiabatic model is developed for the thermal dynamics of the fixed-bed filled with zeolite 13X. The effect of the kinetic parameters on thermal dynamics of the system is investigated, and in particular attention is given to the choice of the isotherm model (Langmuir or Langmuir-Freundlich), the effect of kinetic model (LDF or Vermeulen) and the effect of the mass transfer coefficient between gas and solid phase.

Experiments are done in a lab-scale reactor setup. The numerical and experimental results are compared and are in a good agreement. Based on the comparison between model and experiment it is found that LangmuirFreundlich fit is a better option than a simple Langmuir fit, although using the Langmuir fit makes the simulation faster. The optimum value of the mass transfer coefficient is determined to be around $4.0 \times 10^{-3} \mathrm{~s}^{-1}$. From this work, predictions of the thermal dynamics in the lab-scale reactor are achieved for the case of water vapor sorption in a zeolite $13 \mathrm{X}$ bed. The developed model will be used for further studies on the design and optimization of the new thermochemical heat storage system. Since mass and heat transfer are determining phenomena dictating the performance of a reactor, accurate models describing these phenomena are indispensable tools to come to an efficient design of a large-scale thermochemical heat storage system.

\section{REFERENCES}

[1] Ahn, H. and Lee, C.-H., "Effects of capillary condensation on adsorption and thermal desorption dynamics of water in zeolite 13x and layered beds," Chemical engineering science, 59(13), pp. 2727-2743, (2004).

[2] Bejan, A., Convection heat transfer, John Wiley \& Sons, (2013).

[3] Chapman, S. and Cowling, T. G., The Mathematical Theory of Non-Uniform Gases, Cambridge University Press, Cambridge, (1960).

[4] Crittenden, B. and Thomas, W. J., Adsorption Technology \& Design, Butterworth-Heinemann, (1998). 
[5] Dawoud, B., Vedder, U., Amer, E.-H., and Dunne, S., "Non-isothermal adsorption kinetics of water vapour into a consolidated zeolite layer," International Journal of Heat and Mass Transfer, 50(11), pp. 2190-2199, (2007).

[6] Hawes, D., Feldman, D., and Banu, D., "Latent heat storage in building materials," Energy and Buildings, 20(1), pp. 77-86, (1993).

[7] Kamdem, S. M., Johannes, K., Kuznik, F., Bouia, H., and Roux, J. J., "Theoretical study of heat and mass transfer in a thermo chemical heat storage bed," Proc. of 2nd International Conference on Sustainable Energy Storage, Trinity College Dublin, Ireland, (2012).

[8] Kandula, M., "On the effective thermal conductivity of porous packed beds with uniform spherical particles," Journal of Porous Media, 14(10), (2011).

[9] Leva, M., "Fluid flow through packed beds," Chemical Engineering Science, 56(115), (1949).

[10] Nieminen, J., "Low-energy residential housing," Energy and Buildings, 21(3), pp. 187 - 197, (1994).

[11] Ruthven, D. M., Principle of Adsorption and Adsorption Processes, John Wiley \& Sons, (1984).

[12] Ryu, Y. K., Lee, S. J., Kim, J. W., and Leef, C.-H., “Adsorption equilibrium and kinetics of h2o on zeolite 13x," Korean Journal of Chemical Engineering, 18(4), pp. 525-530, (2001).

[13] Saheb, Y., "Modernising building energy codes to secure our global energy future," The IEA Policy Pathway series, (2011).

[14] Schnieders, J., "Cepheus-measurement results from more than 100 dwelling units in passive houses," European Council for an Energy Efficient Economy: Summer Study, 2003, (2003).

[15] Thomsen, K. E., Schultz, J. M., and Poel, B., "Measured performance of 12 demonstration projects iea task 13 advanced solar low energy buildings," Energy and Buildings, 37(2), pp. 111-119, (2005).

[16] Tommerup, H., Rose, J., and Svendsen, S., "Energy-efficient houses built according to the energy performance requirements introduced in denmark in 2006," Energy and Buildings, 39(10), pp. 1123-1130, (2007).

[17] Vermeulen, T., "Theory for irreversible and constant-pattern solid diffusion," Industrial \& Engineering Chemistry, 45(8), pp. 1664-1670, (1953).

[18] Wakao, N. and Funazkri, T., "Effect of fluid dispersion coefficients on particle-to-fluid mass transfer coefficients in packed beds: Correlation of sherwood numbers," Chemical Engineering Science, 33(10), pp. 1375-1384, (1978).

[19] Xue, B., Tahara, K., Nakashima, K., Noda, A., Oktariani, E., Wijayanta, A. T., Nakaso, K., and Fukai, J., “Numerical simulation for steam generation process in a novel zeolite-water adsorption heat pump," Journal of Chemical Engineering of Japan, 45(6), pp. 408-416, (2012).

[20] Zondag, H., Kalbasenka, A., van Essen, M., Bleijendaal, L., Schuitema, R., van Helden, W., and Krosse, L., "First studies in reactor concepts for thermochemical storage," Proc. of Eurosun, (2009).

[21] Zondag, H., Schuitema, R., Bleijendaal, L., Gores, J. C., van Essen, V., Van Helden, W., and Bakker, M., "R\&d of thermochemical reactor concepts to enable seasonal heat storage of solar energy in residential houses," Proceedings of the ASME 2009 3rd international conference of energy sustainability, San Francisco, California, USA, (2009). 